\title{
FORECASTING MEASLES VACCINE REQUIREMENT BY USING TIME SERIES ANALYSIS
}

\author{
Varsharani Vithalrao Kendre', Jagganath V. Dixit ${ }^{2}$, Vaishali N. Bahattare ${ }^{3}$, Atul V. Wadagale 4
}

${ }^{1}$ Assistant Professor, Department of Community Medicine, Government Medical College, Latur.

2Professor and HOD, Department of Community Medicine, Government Medical College, Latur.

${ }_{3}^{3}$ Assistant Professor, Department of Community Medicine, SRTR Medical College, Ambajogai.

${ }^{4}$ Assistant Professor-Cum-Statistician, Department of Community Medicine, Government Medical College, Latur.

\section{ABSTRACT}

\section{BACKGROUND}

Child Immunisation is an important activity and is carried out at all levels of health care services. At Primary Health Centres and subcentres, vaccine requirement is calculated by fixed formula. It is difficult to estimate vaccine requirement where denominator is not known as in the case of the Government Medical College.

The objective of this study is to forecast Measles vaccine requirement by using time series analysis, at Government Medical College, Latur.

\section{MATERIALS AND METHODS}

The present study was record based; undertaken at Government Medical College, Latur. The data regarding Measles vaccine used during the years 2009-10 to 2014-15 was taken from immunisation book. This month wise data was fed in MS-excel and analysed using software SPSS version 21.0. Method used for time series analysis was Expert Modeller for best model fit. Time series analysis and forecasting was done using best-fit model i.e. Simple seasonal model for measles vaccine.

\section{RESULTS}

A total of 8015 doses of measles vaccine were given during the years 2009-10 to 2014-15 at Government Medical College, Latur. Ljung-Box Q statistics was not significant. Forecasting for Measles vaccine was done up to 2018-19. The vaccine requirement calculated for August 2018 is 134 with 225 and 42 as upper and lower confidence level. It was 136 for February 2019 with 231 and 40 as upper and lower confidence level respectively.

\section{CONCLUSION}

Simple seasonal model of Time series analysis can be used to forecast Measles vaccine requirement at Medical Colleges.

\section{KEYWORDS}

Measles Vaccine Estimation, Time Series Analysis, Simple Seasonal Model.

HOW TO CITE THIS ARTICLE: Kendre VV, Dixit JV, Bahattare VN, et al. Forecasting measles vaccine requirement by using time series analysis. J. Evolution Med. Dent. Sci. 2017;6(28):2329-2333, DOI: 10.14260/Jemds/2017/501

\section{BACKGROUND}

Immunisation is one of the most cost effective public health interventions and was first introduced in India in 1978. ${ }^{1}$ This important activity is carried out through Primary Health Centres, Subcentres, Rural Hospitals, Tertiary Care Hospitals, etc. The live attenuated vaccines are derived from diseasecausing viruses or bacteria that have been weakened under laboratory conditions. They replicate in a vaccinated individual, but because they are weak, they cause either no disease or only a mild form of the disease. Examples are BCG, Measles and the Oral Polio Vaccine. The MoHFW, Govt. of India launched Mission Indradhanush in December 2014 as a special drive to vaccinate all unvaccinated and partially vaccinated children under UIP. ${ }^{2}$

Traditionally vaccine requirement is estimated with the following steps especially, where head count is known or can

Financial or Other, Competing Interest: None.

Submission 21-02-2017, Peer Review 24-03-2017,

Acceptance 31-03-2017, Published 06-04-2017.

Corresponding Author:

Dr.Varsharani Vithalrao Kendre,

"Varsha Residency", Plot No .77,

Bhakti Nagar, New Renapur Naka,

Sai Road, Latur-413512,

Maharashtra.

E-mail: mundevarsharani@gmail.com

DOI: $10.14260 /$ jemds $/ 2017 / 501$

\section{(c) $($ ) $\Theta$}

be done i.e. denominator. The head count can be conducted through the

Community Needs Assessment Approach or the biannual/annual survey method. For infants, the headcount would provide a point estimate for the year. From that, monthly estimate is calculated. A wastage rate of $25 \%$ or a wastage multiplication factor (WMF) of 1.33 is allowed for all vaccines. So, the wastage multiplication factor for Measles vaccine, is also $1.33 . .^{2}$

Time series analysis is a specialised area of statistics to which many marketing researchers have had limited exposure, despite it having many important applications in Marketing research. Two popular univariate time series methods are exponential smoothing (e.g., Holt-Winters) and ARIMA (autoregressive integrated moving average). ${ }^{3}$ Forecasting techniques are important tools in operational management for creating realistic expectations. ${ }^{4}$

So this study was conducted to estimate vaccine requirement where head count cannot be done; for ex. Medical colleges, where people come from various districts and their number is not fixed i.e. denominator is not known.

\section{Objective}

To forecast Measles vaccine requirement by using time series analysis, at Government Medical College, Latur. 


\section{MATERIALS AND METHODS}

\section{Study Design}

The present study was cross sectional; record based study.

\section{Study Setting}

Government Medical College, Latur; A Tertiary Care Hospital attached to Government Medical College.

\section{Data Collection}

The data regarding Measles vaccine used during previous six years i.e. from 2009-10 to 2014-15 was collected from Immunisation Report Book maintained at Immunisation Clinic of Government Medical College .

The month wise data of above six years was fed in MSexcel. This pre-processed data was then imported in Statistical Package for Social Sciences (SPSS) version 21.0 and statistical analysis was done.

Then, following steps were followed: analyse- for castingcreate models. Method used was Expert Modeler. While there was another method called ARIMA, we used Expert Modeler for best model fit. In statistics, we display fit of measures Ljung-Box statistics and number of outliers by given model.

For comparing models, we used stationary $\mathrm{R}^{2}$, normalised BIC, as model fit statistics and for individual models, we used ACF and PACF plot. In autocorrelation and partial correlations we used natural log transform with difference of 1. The lags used for study were 24 . Time series analysis and forecasting was done using best-fit models i.e. Simple seasonal model using SPSS version 21.0.

\section{RESULTS}

A total of 8015 doses of Measles vaccine were given during the years 2009-10 to 2014-15 at Government Medical
College, Latur. Maximum number of doses were given during the year 2014 and minimum number of doses were given during 2009. Average number of doses and standard deviation is shown in Table 1.

The autocorrelation function (ACF) and partial autocorrelation functions (PACF) were not significant at any lag for the series of Measles vaccine indicating stationarity of the series which is shown in Fig. 1 and Fig. 2. Expert Modeler of SPSS ver. 21 suggested simple seasonal model as the best fit statistical model for Measles vaccine time series data.

Table 2 Shows model statistics. $\mathrm{R}$ squared value for Measles model was 0.758 . Here, stationary $R$-squared value was used for comparing models since it provides an estimate of the proportion of the total variation in the series that is explained by the model. This table also shows the Ljung-Box $\mathrm{Q}$ statistics and its $\mathrm{P}$-value. It was not significant for Measles model ( $p=0.707)$. The model detected no outlier in the data.

Table 3 shows exponential smoothing model parameters. It shows values of alpha (level) and delta (season) for BCG model. Here, alpha value is indicating prominence of level component in the model with very less seasonal component.

Table 4 shows the Year-wise forecasts for Measles vaccine provided by Simple seasonal model with their upper and lower confidence level. Forecasting was done using the best model selected i.e. simple seasonal model till 2018-19 for Measles vaccine. From this table, we can see that the vaccine requirement for August 2018 is 134 with 225 and 42 as upper and lower confidence level. It was 136 for February 2019 with 231 and 40 as upper and lower confidence level respectively.

Fig. 3 shows the Measles vaccine forecast. It shows wide confidence interval over time.

\begin{tabular}{|c|c|c|c|c|c|c|}
\hline Month/Year & $\mathbf{2 0 0 9}$ & $\mathbf{2 0 1 0}$ & $\mathbf{2 0 1 1}$ & $\mathbf{2 0 1 2}$ & $\mathbf{2 0 1 3}$ & $\mathbf{2 0 1 4}$ \\
\hline April & 92 & 66 & 110 & 64 & 112 & 170 \\
\hline May & 119 & 81 & 0 & 107 & 136 & 140 \\
\hline June & 99 & 82 & 161 & 74 & 100 & 130 \\
\hline July & 106 & 64 & 113 & 126 & 164 & 134 \\
\hline August & 63 & 59 & 96 & 106 & 134 & 154 \\
\hline September & 90 & 82 & 74 & 118 & 149 & 133 \\
\hline October & 106 & 88 & 44 & 114 & 168 & 140 \\
\hline November & 91 & 81 & 82 & 90 & 135 & 220 \\
\hline December & 106 & 141 & 77 & 150 & 174 & 130 \\
\hline January & 130 & 105 & 72 & 108 & 165 & 160 \\
\hline February & 82 & 109 & 85 & 130 & 118 & 100 \\
\hline March & 61 & 137 & 116 & 99 & 133 & 160 \\
\hline Total & 1145 & 1095 & 1030 & 1286 & 1688 & 1771 \\
\hline Mean & 95.41667 & 91.25 & 85.83333 & 107.1667 & 140.6667 & 147.5833 \\
\hline S.D. & 20.39812 & 26.77219 & 39.91772 & 23.74422 & 23.76144 & 29.37364 \\
\hline \multicolumn{7}{|c|}{ Table 1. Year-wise and Month-wise Measles Doses Used } \\
\hline
\end{tabular}

\begin{tabular}{|c|c|c|c|c|c|c|c|}
\hline Model & $\begin{array}{c}\text { No. of } \\
\text { Predictors }\end{array}$ & \multicolumn{2}{|c|}{ Model Fit Statistics } & \multicolumn{2}{c|}{ Ljung-Box Q(18) } & $\begin{array}{c}\text { Number of } \\
\text { Outliers }\end{array}$ \\
\hline & & $\begin{array}{c}\text { Stationary R- } \\
\text { Squared }\end{array}$ & $\begin{array}{c}\text { Normalised } \\
\text { BIC }\end{array}$ & Statistics & DF & Sig. & \\
\hline $\begin{array}{c}\text { Measles- } \\
\text { Model_1 }\end{array}$ & 0 & .758 & 6.817 & 12.527 & 16 & .707 & 0 \\
\hline \multicolumn{7}{|c|}{ Table 2. Model Statistics } \\
\hline
\end{tabular}




\begin{tabular}{|c|c|c|c|c|c|c|}
\hline Model & & & Estimate & SE & T & Sig. \\
\hline \multirow{2}{*}{ Measles-model_1 } & \multirow{2}{*}{ No Transformation } & Alpha (Level) & .200 & .072 & 2.774 & .007 \\
\cline { 3 - 7 } & \multicolumn{1}{|c|}{$\begin{array}{c}\text { Delta } \\
\text { (Season) }\end{array}$} & $2.792 \mathrm{E}-005$ & .127 & .000 & 1.000 \\
\hline \multicolumn{7}{|c|}{ Table 3. Exponential Smoothing Model Parameters } \\
\hline
\end{tabular}

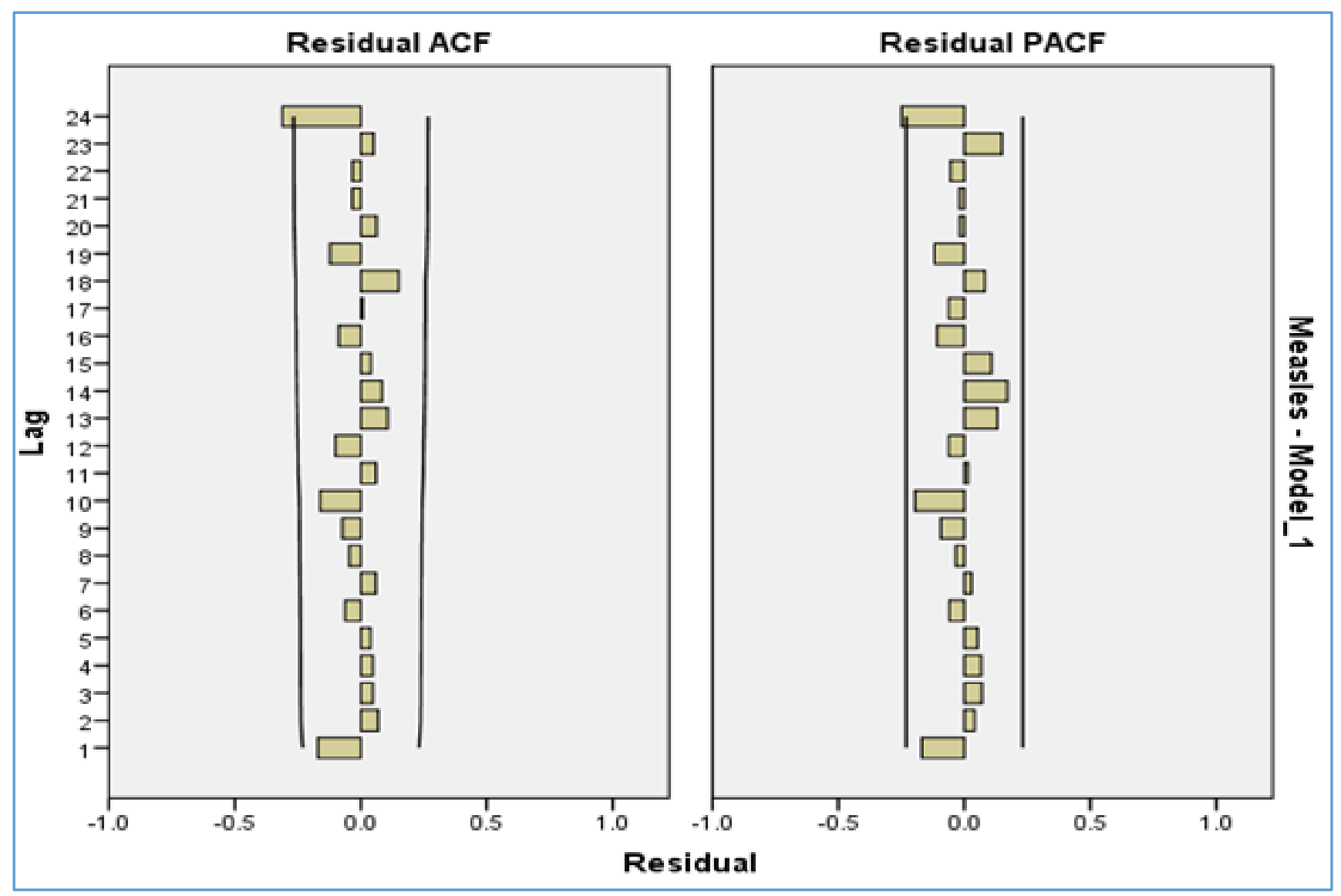

Figure 1

Figure 2

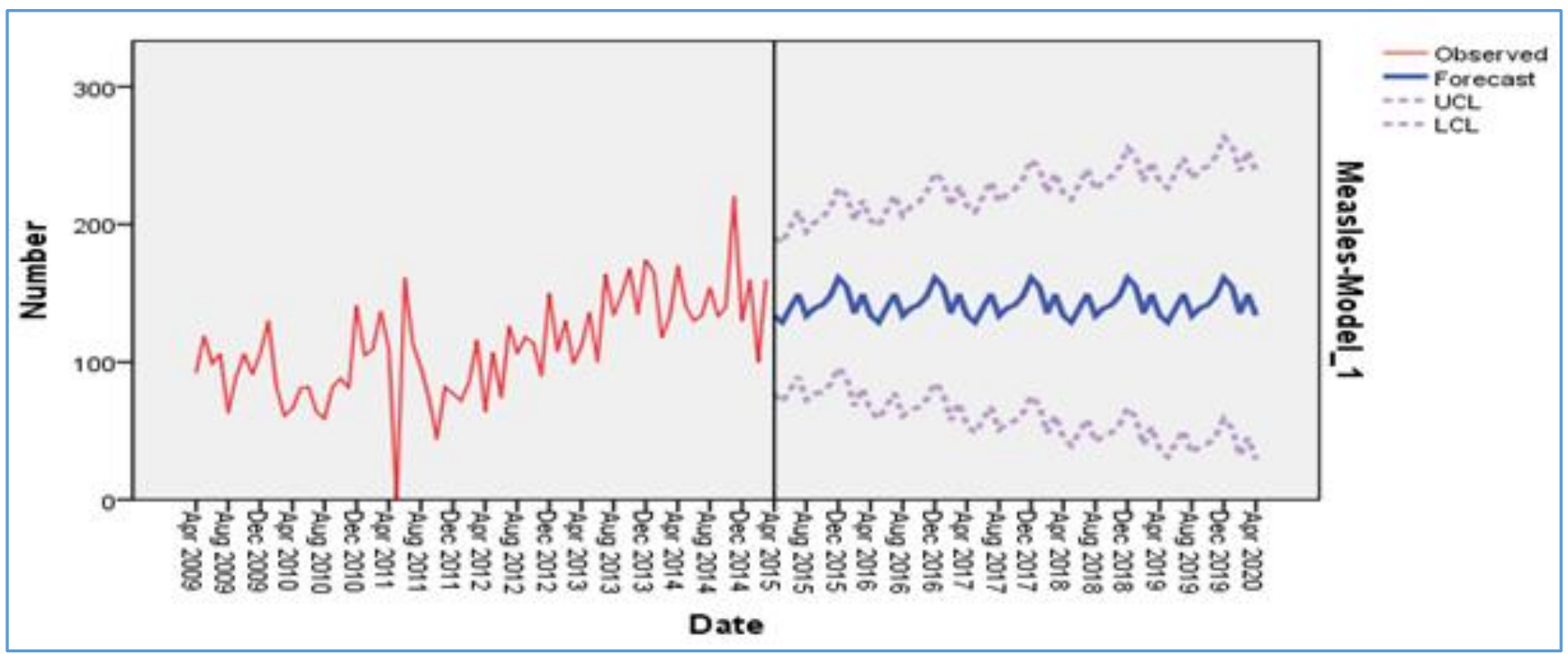

Figure 3. Measles Forecast 


\begin{tabular}{|c|c|c|c|}
\hline \multirow[t]{2}{*}{ Model } & \multicolumn{3}{|c|}{ Measles -Model_1 } \\
\hline & Forecast & UCL & LCL \\
\hline Apr. 2015 & 134 & 191 & 77 \\
\hline May. 2015 & 129 & 187 & 71 \\
\hline Jun. 2015 & 139 & 198 & 80 \\
\hline Jul. 2015 & 149 & 209 & 89 \\
\hline Aug. 2015 & 134 & 195 & 72 \\
\hline Sep. 2015 & 139 & 201 & 77 \\
\hline Oct. 2015 & 142 & 205 & 78 \\
\hline Nov. 2015 & 148 & 212 & 84 \\
\hline Dec. 2015 & 161 & 226 & 96 \\
\hline Jan. 2016 & 155 & 221 & 89 \\
\hline Feb. 2016 & 136 & 203 & 68 \\
\hline Mar. 2016 & 149 & 217 & 81 \\
\hline Apr. 2016 & 134 & 203 & 65 \\
\hline May. 2016 & 129 & 199 & 59 \\
\hline Jun. 2016 & 139 & 210 & 68 \\
\hline Jul. 2016 & 149 & 221 & 78 \\
\hline Aug. 2016 & 134 & 206 & 61 \\
\hline Sep. 2016 & 139 & 213 & 66 \\
\hline Oct. 2016 & 142 & 216 & 67 \\
\hline Nov. 2016 & 148 & 223 & 73 \\
\hline Dec. 2016 & 161 & 237 & 85 \\
\hline Jan. 2017 & 155 & 232 & 78 \\
\hline Feb. 2017 & 136 & 213 & 58 \\
\hline Mar. 2017 & 149 & 228 & 71 \\
\hline Apr. 2017 & 134 & 213 & 54 \\
\hline May. 2017 & 129 & 209 & 48 \\
\hline Jun. 2017 & 139 & 220 & 58 \\
\hline Jul. 2017 & 149 & 231 & 67 \\
\hline Aug. 2017 & 134 & 216 & 51 \\
\hline Sep. 2017 & 139 & 220 & 58 \\
\hline Oct. 2017 & 142 & 226 & 57 \\
\hline Nov. 2017 & 148 & 233 & 63 \\
\hline Dec. 2017 & 161 & 247 & 75 \\
\hline Jan. 2018 & 155 & 241 & 68 \\
\hline Feb. 2018 & 136 & 223 & 48 \\
\hline Mar. 2018 & 149 & 237 & 61 \\
\hline Apr. 2018 & 134 & 223 & 45 \\
\hline May. 2018 & 129 & 218 & 39 \\
\hline Jun. 2018 & 139 & 229 & 49 \\
\hline Jul. 2018 & 149 & 240 & 59 \\
\hline Aug. 2018 & 134 & 225 & 42 \\
\hline Sep. 2018 & 139 & 231 & 47 \\
\hline Oct. 2018 & 142 & 234 & 49 \\
\hline Nov. 2018 & 148 & 242 & 54 \\
\hline Dec. 2018 & 161 & 256 & 67 \\
\hline Jan. 2019 & 155 & 250 & 60 \\
\hline Feb. 2019 & 136 & 231 & 40 \\
\hline Mar. 2019 & 149 & 246 & 53 \\
\hline Table 4. Year-w & $\begin{array}{l}\text { ists for } N \\
\text { Season }\end{array}$ & accin & ovidec \\
\hline
\end{tabular}

Varun Kumar,6,7 Sachin S Mumbare. ${ }^{8}$ Emrah Onder ${ }^{4}$ used exponential smoothing model in his study.

Sachin S Mumbare ${ }^{8}$ in his study used Box-Jenkins ARIMA $(p, d, q)$; autoregressive integrated moving averages; nonseasonal models for the analysis and forecasting the average number of children at the time of terminal contraception in each group, till 2020.

He found the time series to be non-stationary, as interpreted by augmented Dickey-Fuller test, so the series was analysed with $d \geq 1$. He compared results of the different models using fit measures like R-square, stationary R-square, mean absolute percentage error, maximum absolute percentage error, and normalised Bayesian Information Criteria. Using these parameters, he identified best-fit model for each group. Also, confirmed the best-fit model using Expert Modeler in SPSS and tested adequacy of the best-fit model by examining autocorrelation function of the residuals. Ljung-Box test statistics was used for the same, similar to the present study. The model was ignored, if the Ljung-Box $Q$ statistics gave significant $\mathrm{P}$-value.

Varun Kumar 6 in his study on forecasting Malaria Cases Using Climatic Factors in Delhi checked stationarity of the data by autocorrelation function (ACF) and partial autocorrelation function (PACF) which showed a significant peak at a lag of 12 which confirmed the presence of seasonal component in the time series data. These findings were different from the present study where ACF and PACF do not showed significant peak at lag 12. Ljung-Box (modified BoxPierce) test was used in his study to determine if the model was correctly specified, similar to the study ${ }^{8}$ and present study. He used ARIMA $(0,1,1)(0,1,0)$ as suggested by Expert Modeler of SPSS ver. 21 as the best fit statistical model for the same.

In the present study, Stationary $R$-squared value was used as model statistics as it is preferable to ordinary $R$-squared when there is a trend or seasonal pattern. Larger values of stationary $R$-squared (up to a maximum value of 1 ) indicate better fit. 6

Varun Kumar $^{7}$ in his study on Seasonality of Tuberculosis in Delhi used ARIMA model for seasonality which showed both declining trend and periodic seasonal fluctuations. Seasonal variation was more in his study as compared to the present study.

Win Wah ${ }^{9}$ used the seasonal autoregressive moving average (SARIMA), ARIMA models with periodic components, to predict the temporal trends of the more volatile monthly TB risk among residents and non-residents in Singapore and detect seasonality. The model with the lowest value of the AIC (Akaike's Information Criterion) was selected to analyse yearly TB cases.

Using a time series analysis, an exponential model was fitted to the annual incidence rates of suicide (by any method) between 1995 and 2009. Model adequacy was tested using the mean absolute percentage error (MAPE), a measure of how much a dependent series varies from its model-predicted level. Larger values of stationary $R$-squared (Up to a maximum value of 1 ) indicate better fit. A value of 0.758 meant that the model could explain $75 \%$ of the observed variation in the series. A seasonal pattern exists when a series is influenced by seasonal factor (e.g.-the quarter of the year, the month, or day of week). Seasonality is always fixed and of known period. 10 
Exponential smoothing models are classified as either seasonal or non-seasonal. Simple seasonal model is appropriate for series with no trend and seasonal effect that is constant over time. Its only relevant parameter is smoothing. 11

\section{CONCLUSION}

Expert Modeler was used in this study of time series analysis, it showed simple seasonal model as best fit model which is the type of exponential smoothing. It can be used to forecast vaccine requirement in case of Measles vaccine; as Ljung Box $\mathrm{Q}$ statistics was not significant.

Time series analysis and forecasting is an objective method for calculating vaccine requirement as it gives the values with upper and lower confidence interval. It assures optimum supply of vaccine. So it can be used in Medical colleges.

\section{ACKNOWLEDGMENTS}

The authors are thankful to Dr. Mumbare S.S., Professor and Head, Ashwini Research Institute, Kumbhari for his guidance and help.

\section{REFERENCES}

[1] Immunization handbook for medical officers: Department of Health and Family Welfare, Ministry of Health and Family Welfare, Government of India, 2008.

[2] Guidelines for Reporting \& Management of Adverse Events Following:

Immunization: India, New Delhi, Government of India, 2005. http://www.whoindia.org/LinkFiles/Routine _Immunization_AEFIguidelines_for_reporting.pdf.
[3] Kelvin G. Time series analysis-what it is and what it does. Available from: http://www.quirks.com/articles/time-series.

[4] Emrah Ö, Ali H. Combining time series analysis and multi criteria decision making techniques for forecasting financial performance of banks in Turkey. Int J of Latest Trends in Fin \& Eco Sc 2013;3(3):53055.

[5] Duke. Moving average and exponential smoothing models 2016. Available from: http://people.duke.edu>rnau.

[6] Varun K, Abha M, Sanjeet P, et al. Forecasting malaria cases using climatic factors in Delhi, India: a time series analysis. Malaria Research and Treatment 2014;Article ID 482851:1-6.

[7] Varun K, Abhay S, Mrinmoy A, et al. Seasonality of tuberculosis in Delhi, India: a time series analysis. Tuberc Res Treat 2014;Article ID 514093:1-5.

[8] Sachin SM, Shriram G, Balaji A, et al. Trends in average living children at the time of terminal contraception: a time series analysis over 27 years using ARIMA (p, d, q) nonseasonal model. Indian J Community Med 2014;39(4):223-8.

[9] Hyndman RJ. Cyclic and seasonal time series Hyndsight 2011. Available from: http://robjhyndman.com> hindsight $>$ cyclists.

[10] Win W, Sourav D, Arul E, et al. Time series analysis of demographic and temporal trends of tuberculosis in Singapore. BMC Public Health 2014;14:1121.

[11] Time series exponential smoothing criteria-IBM, 2016. Available from: http://www.ibm.com>knowledgecenter. 